\title{
GEOELECTRICAL APPROACH FOR DIFFERENTIATING THE HYDROGEOLOGICAL SECTION IN THE STUDY OF A TAILINGS POND SITE
}

DOI: http://dx.doi.org/10.18509/GBP.2020.16

UDC: 550.373:556.551]:639.311(497.2)

\author{
Nikolay Stoyanov ${ }^{1}$ \\ Stefan Dimovski \\ University of Mining and Geology "St. Ivan Rilski” Faculty of Geoexploration, Bulgaria \\ ${ }^{1}$ Department of Hydrogeology and Engineering Geology \\ ${ }^{2}$ Department of Applied Geophysics
}

\begin{abstract}
An important issue in the construction of tailings ponds is the detailed knowledge of the hydrogeological section beneath the bottom of the facility. The answer to this question can hardly be achieved only by a standard drilling survey, especially in regions with complex geological structure where the identification of small in size, highly permeable areas requires a high density of the borehole network. The proposed geoelectrical approach for mapping the low-rank hydrogeological units forming the tailings dam basement involves the application of the electrical resistivity tomography method. The subsurface geoelectrical model obtained by this method is transformed into a hydrogeological model on the base of data from the performed standard core drilling survey and slug tests. The applicability and high efficiency of the proposed integrated approach is demonstrated by the results from the study of a site for construction of a tailings pond near Breznik, Bulgaria.
\end{abstract}

Keywords: ERT method, hydrogeological surveying, tailings pond, geoelectrical model, groundwater protection

\section{INTRODUCTION}

In recent years, the ERT method has established itself as a very useful tool in mapping the near-surface geological section [1], [2], [3]. Our previous research efforts and experience show that its combined application with various other techniques enables a much more precise delineation of the spatial boundaries of geological and hydrogeological units, tectonic faults, fissured and karst zones, water saturated and unsaturated zones, zones characterized by a different degree of water permeability, contaminated areas, landslides, etc. [4], [5], [6], [7], [8], [9], [10], [11], [12].

This approach has been successfully tested during a complex survey performed by our team. The objective was to outline layers and zones with different water permeability in the geological section of a potential site for construction of a tailings pond near Breznik, West Bulgaria (Figure 1).

The study involved the application of various tools for surface survey - the ERT method, exploratory core drilling and slug tests. The accomplished quantitative assessments of the hydrogeological conditions in the area are based on a comprehensive analysis of all the results obtained. 


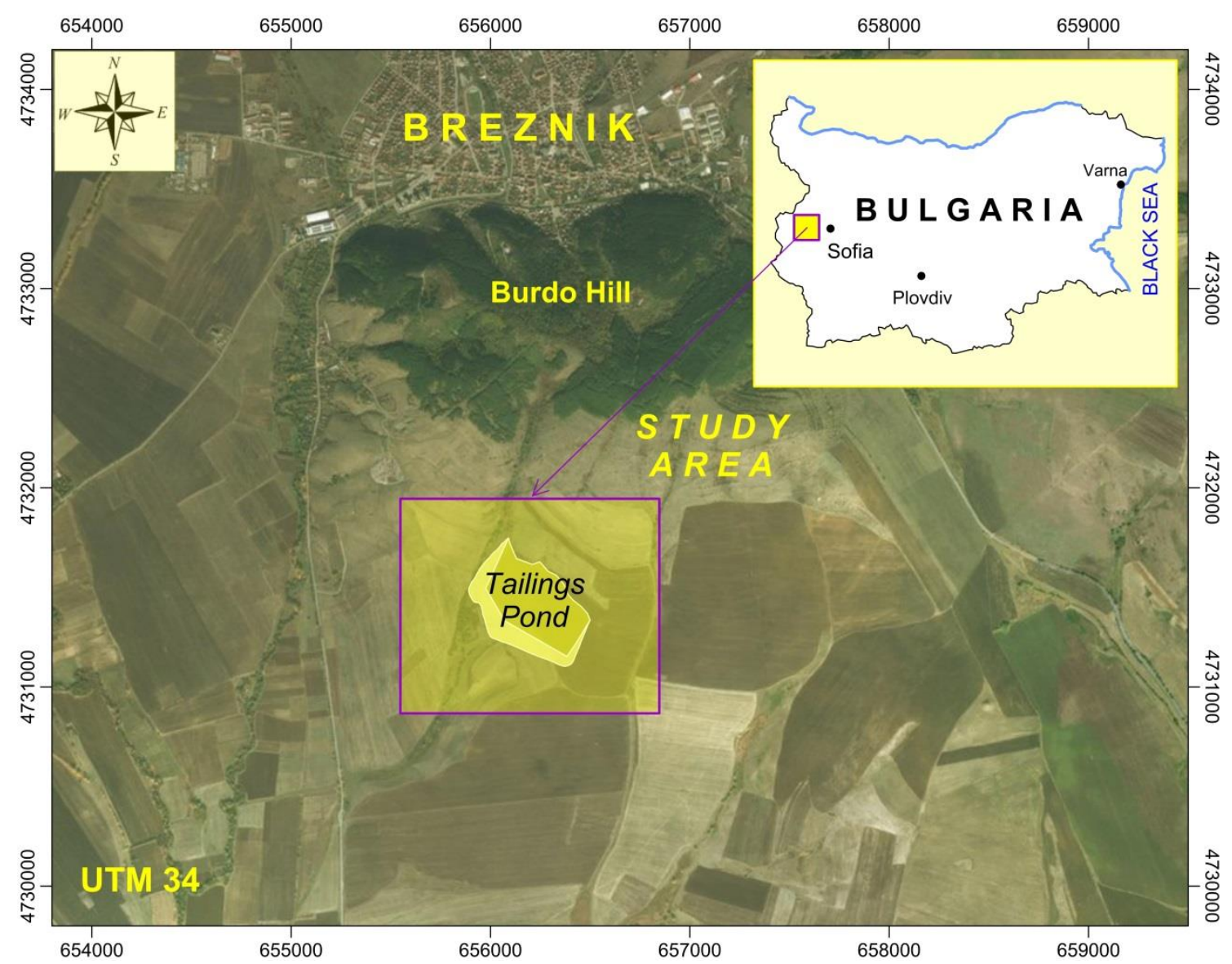

Figure 1. Location of the study area in the region of Breznik, West Bulgaria

\section{GEOLOGICAL BACKGROUND}

The potential site for construction of a tailings pond is located to the south of the town of Breznik, on the southern slopes of the Burdo hill. The terrain is flat with a slight slope to the southwest. The geological structure is very complex, dominated by volcanic and volcanogenic-sedimentary rock types of Upper Cretaceous age. Frequent changes in lithological composition and genetic type of rocks are characteristic for the studied area. The central and western parts of the site are composed mainly of psammitic-aleurolitic tuffs and partly of agglomerate tuffs and andesite lava flows. These volcanic rocks intersect and partially overlap the older volcanogenic-sedimentary formation built of alternating tuffs, tuffites and marls. To the south and west, a volcanic formation of lava spills, layered and transecting bodies, predominantly composed of trachyandesites, is revealed. The same rocks alternate with the marl complex in the periphery of the volcanogenic-sedimentary formation.

Everywhere, at the top of the section, the rocks are highly to moderately weathered, affected by secondary alteration, and at some locations decomposed to clay. At some places, Quaternary deluvial clays, sandy clays and gravelly clays, interbedded with thin sandy clay layers, overlie the Upper Cretaceous rocks. Their total thickness changes from 1 to $10 \mathrm{~m}$ or more.

The groundwater level in the area of the potential site for construction of a tailings pond varies over a very wide range - from 2.0 to $10.6 \mathrm{~m}$ below land-surface datum. 


\section{METHODS AND INSTRUMENTS}

The geoelectrical approach for differentiating the hydrogeological section of the potential tailings dam site involved the application of the ERT method, exploratory core drilling and slug tests.

The geoelectrical ERT method was applied to study the near-surface section down to a depth of 30-35 m. The field measurements were made along six electrical tomography lines (ETL) having a total length of $2540 \mathrm{~m}$. The length of each surveying line was respectively: ETL3 - 590 m, ETL4 - 710 m, ETL5 - 250 m, ETL6 - 370 m, ETL7 - 250 $\mathrm{m}$ and ETL8 - $250 \mathrm{~m}$. The exact location of all geophysical surveying lines in the area is presented in Figure 2. Field measurements were performed using a four-electrode Wenner array (10 m electrode spacing) connected to the instrument through two sets of multi-core cable [13]. The registration was achieved with the help of the equipment Terrameter SAS 1000 , manufactured by the Swedish company ABEM. It operates with a $400 \mathrm{~V}$ output voltage and a maximum output current of $1000 \mathrm{~mA}$. The collected data were processed and inverted using the computer program RES2DINV [14], [15]. The analysis of the obtained results was performed taking into account the available information about the geological section in the tailings dam area, the data from the core drilling survey and the slug tests. Reference data for the electrical resistivity of different rock types were also used [16], [17].

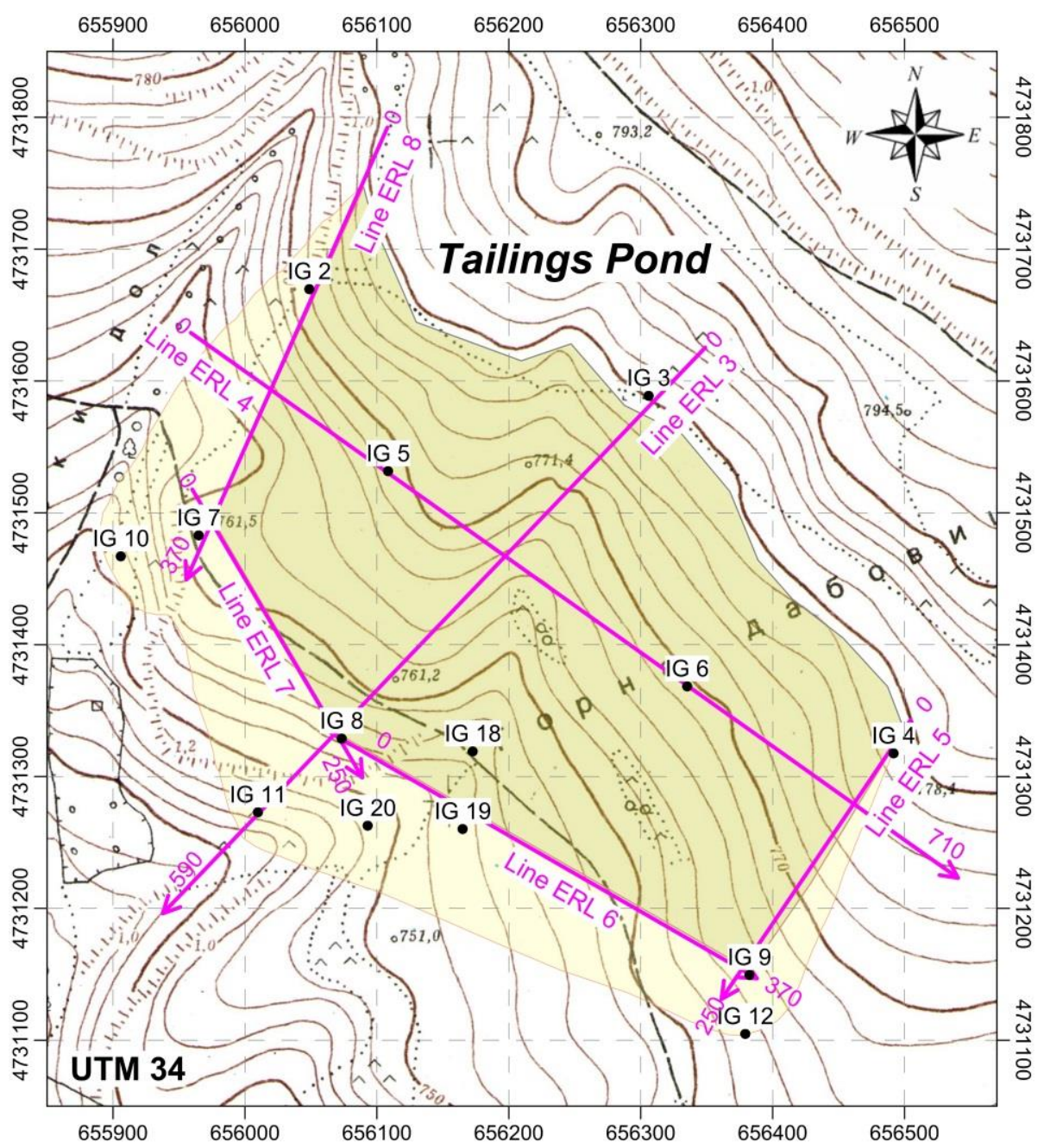

Figure 2. Location of surveyed ERT lines and drilled boreholes 
The exploratory core drilling study involved the construction of 14 boreholes (IG) with depths ranging between 15 and $31 \mathrm{~m}$, only borehole IG8 being $50 \mathrm{~m}$ deep. Their location is given in Figure 2. The lithological sections and groundwater levels established by the boreholes were documented in detail. Subsequently, they were used as identification keys for mapping the spatial boundaries of low-rank hydrogeological units according to electrical tomography survey data.

Eleven slug tests were performed at different intervals in eight of the constructed boreholes - IG-2, IG-5, IG-6, IG-7, IG-8, IG-9, IG-18 and IG-19. The intervals are chosen in order to cover parts of the geological section that are relatively homogeneous according to their lithology and degree of secondary alteration, i.e. within one hydrogeological unit. The procedures applied during the rising-head and falling-head slug tests and the methods for identifying the hydraulic conductivity values are described in detail in [18], [19]. The obtained results were used as an additional key in the determination of low-rank hydrogeological units.

\section{RESULTS AND INTERPRETATION}

The complex analysis of the results of the electrical resistivity tomography and the exploratory core drilling shows that the studied geoelectrical section along the six surveying lines is generally represented by three main electrical resistivity media (zones), two of which include nine sub-zones - Figure 3:

- The first electrical resistivity medium (Zone A) is characterized by the lowest values of electrical resistivity in the studied sections - from 10 to $50 \Omega \mathrm{m}$, up to $80 \Omega \mathrm{m}$ in separate parts. This area maps different in lithology and genesis rock types whose common characteristics are that they are disintegrated and unconsolidated, which is usually the reason for their higher water permeability. Formally, this zone includes the soil layer, the diluvial covering represented by clays, sandy clays and gravelly clays, as well as all highly and moderately weathered rocks, heavily fractured and affected by secondary alteration - tuffs, tuff-breccias, tuffites, marls, sandstones, siltstones and trachyandesites. The total thickness of Zone A varies over a very wide range - from 1 to $25 \mathrm{~m}$, having an average thickness of about 10-15 m. Five sub-zones can be separated in the structure of Zone A, on the basis of minor differences in the electrical resistivity values and in accordance to the borehole lithological sections:

Sub-zone A1 - characterized by values of electrical resistivity from 20 to $45 \Omega \mathrm{m}$, rarely up to $65 \Omega \mathrm{m}$. It probably maps the soil layer and highly weathered andesite breccias and lava breccias.

Sub-zone A2 - has values of electrical resistivity similar to those of Sub-zone A1 from 20 to $45 \Omega \mathrm{m}$, rarely to $75 \Omega \mathrm{m}$. It outlines the soil layer and highly to moderately weathered marls, argillites, sandstones and tuffites. The dominant presence of marls implies low water permeability.

Sub-zone $A 2 s$ - typified by electrical resistivity values of 20 to $45 \Omega \mathrm{m}$, rarely up to 65 $\Omega \mathrm{m}$, which is also characteristic of Sub-zone A1. It maps a rock complex similar to Sub-zone A2, but with dominant presence of siltstones.

Sub-zone $A 2 t$ - has values of electrical resistivity that are generally in the range of 35 to $70 \Omega \mathrm{m}$, very rarely to $80 \Omega \mathrm{m}$. It outlines a rock complex similar to Sub-zone A2, in which trachyandesites are present and in some parts are even predominant.

Sub-zone A3 - characterized by electrical resistivity values from 10 to $50 \Omega \mathrm{m}$. Most likely, it maps the soil layer and the highly to moderately weathered and decomposed to clay trachyandesites. 

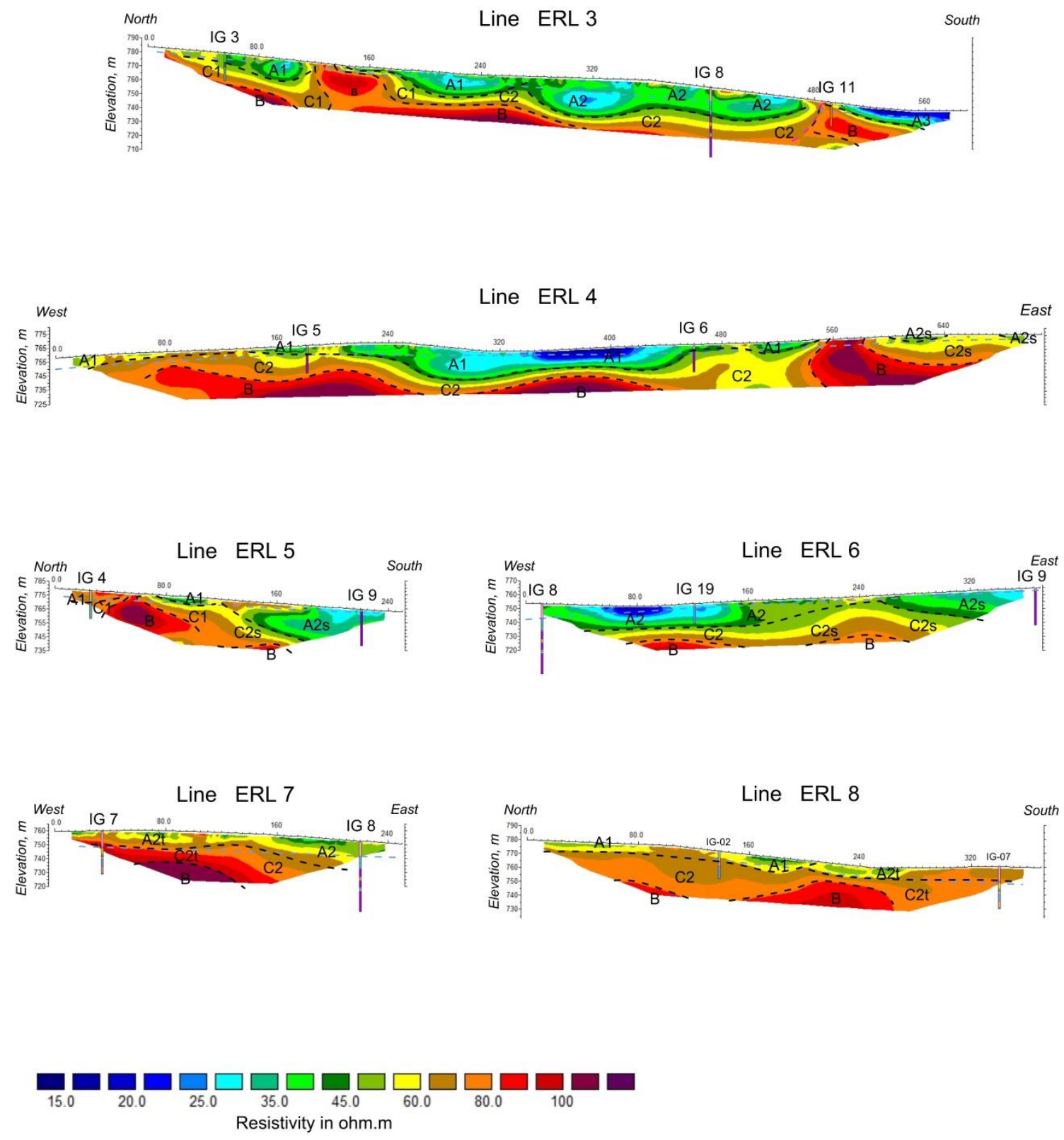

- . - - - Groundwater level (according to borehole data)

- - - - - Boundary between geoelectrical media (zones)

Figure 3. Geoelectrical sections along the surveyed lines. Boundaries between the electrical resistivity zones.

- The second electrical resistivity medium (Zone B) has the highest values of electrical resistivity in the studied sections - from 85 to $300 \Omega \mathrm{m}$ and more. Zone B maps moderately weathered and fractured trachyandesites and, in depth, less weathered parts of the rock complex. Low water permeability is assumed.

- The third electrical resistivity medium (Zone C) is situated between the other two main electrical resistivity media. It is characterized by values of electrical resistivity in the range of 45 to $100 \Omega \mathrm{m}$. This zone maps slightly to moderately weathered and fractured rocks, different in lithology and genesis - tuffs, tuffites, tuff-breccias, marls, sandstones. It has a relatively lower permeability than zone A. Four sub-zones can be 
separated in the structure of Zone $\mathrm{C}$, based on the observed differences in the electrical resistivity values and in accordance to the borehole lithological sections:

Sub-zone $C 1$ - characterized by values of electrical resistivity from 45 to $80 \Omega \mathrm{m}$. It maps slightly weathered tuffs and andesite breccias.

Sub-zone C2 - has values of electrical resistivity similar to those of Sub-zone C1 from 45 to $80 \Omega \mathrm{m}$, rarely to $90 \Omega \mathrm{m}$. It outlines a slightly to moderately weathered rock complex built of marls, sandstones and tuffs.

Sub-zone $C 2 s$ - typified by electrical resistivity values of 45 to $75 \Omega \mathrm{m}$. It maps a rock complex similar to Sub-zone C2, but with dominant presence of siltstones.

Sub-zone $C 2 t$ - has relatively higher values of electrical resistivity, typically from 65 to $100 \Omega \mathrm{m}$. It outlines a similar rock complex, but with dominant presence of trachyandesites.

Based on the acquired electrical resistivity sections along the six lines (Figure 3), two high rank hydrogeological units (HGU), composed by five low rank hydrogeological units (zones), were separated in the area of the potential site for construction of a tailings pond down to a depth of 30-35 $\mathrm{m}$ (Table 1). The spatial boundaries of these formations are illustrated in the compiled hydrogeological sections along the surveying lines (Figure 4). In the transformation of the geoelectrical model into a hydrogeological model, the documented lithological sections in the boreholes, the hydraulic conductivity values derived from the performed slug tests and the registered groundwater levels were used as identification keys. The so determined hydrogeological units have the following characteristics:

- Upper permeable layer (HGU1) - It covers the near-surface section down to a depth of 2 to $30 \mathrm{~m}$. The upper part is made of clay and sandy clay with sandy layers, whose total thickness varies between 1 and $9 \mathrm{~m}$. Beneath these deposits, the hydrogeological section is represented by heavily weathered and fractured rocks - tuff-breccias, tuffs, tuffites, marls, siltstones and trachyandesites, in places decomposed to gravelly clay and clays with rock fragments. The presence of areas with marked differences in lithological composition, degree of rocks secondary alteration and grain size of the secondary products suggests noticeable dissimilarities in the water permeability of the geological environment. According to this characteristic, three low rank hydrogeological units are separated into the HGU1 structure:

Zone of low to moderate permeability (HGUla) - The clay facies is dominant, which determines the low permeability of the lithological types that make up it. It covers the entire span of HGU-1 layer throughout most of the site, except for small areas around boreholes IG5, IG9 and IG12.

Zone of moderate permeability $(H G U 1 b)$ - It is represented mainly by heavily fractured, in some places even fragmented and decomposed, argillites with thin sandstone layers, at the top covered by diluvial clays 1-2 m thick. The total thickness of zone HGU1b varies between 2-3 and $28 \mathrm{~m}$. It covers a small area in the southeast part of the site around boreholes IG9 and IG12.

Zone of high permeability (HGUlc) - It is mainly made of andesite tuffs, coarsegrained, highly weathered and fractured, overlaid by diluvial silty and sandy clays up to 1-2 m thick. It covers a small area in the central part of the site and is revealed in the cross sections along studied lines HGL3 and HGL4. 

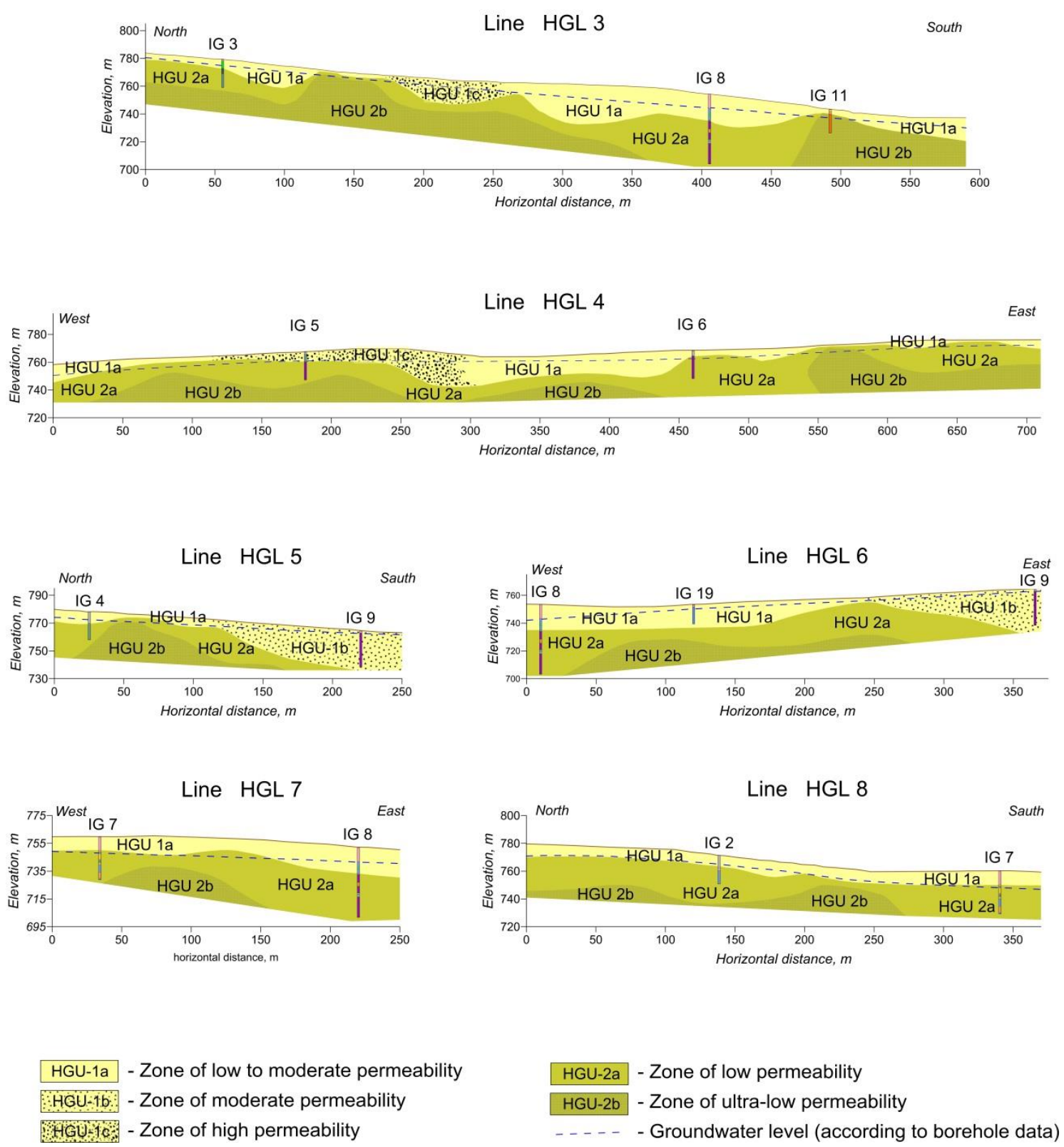

Figure 4. Hydrogeological model. Boundaries between the hydrogeological units.

- Lower layer of low permeability (HGU2) - It is found ubiquitously beneath the HGU1 layer in all hydrogeological cross sections along the six studied lines. It is developed in moderately weathered and fractured volcanic and volcanogenic-sedimentary rocks, and in some places and in depth in the less weathered parts of these rock complexes. Based on the observed differences in lithological composition, degree of secondary alteration and electrical resistivity, two low rank hydrogeological units are separated into the HGU2 structure:

Zone of low permeability (HGU2a) - It is formed in the moderately to slightly weathered and fractured parts of the Lower Cretaceous complex represented by tuffbreccias, tuffs, tuffites, marls, siltstones and trachyandesites. It is revealed in the hydrogeological cross sections on all studied lines in the upper part of the HGU2 layer. Its thickness varies from 1-2 to $35 \mathrm{~m}$ having an average of about 15-20 m. 
Zone of ultra-low permeability (HGU2b) - It is composed of unweathered, slightly fractured and solid rocks (most probably trachyandhesites, lava formations, etc.) with high electrical resistivity. The slight alteration of these rocks implies ultra-low water permeability of the geological basement. The boundary between HGU2a and HGU2b is mapped in accordance with the observed differences in electrical resistivity. The thickness of HGU2b zone probably exceeds $30 \mathrm{~m}$.

Table 1. Hydrogeological units, thicknesses and average hydraulic conductivity values

\begin{tabular}{|c|c|c|c|}
\hline \multicolumn{2}{|c|}{ Hydrogeological units (layers and zones) } & \multirow{2}{*}{$\begin{array}{l}\text { Thickness } \\
\text { from- to- , m }\end{array}$} & \multirow{2}{*}{$\begin{array}{l}\text { Hydraulic } \\
\text { conductivity, m/d }\end{array}$} \\
\hline Layer & Zone & & \\
\hline \multirow{3}{*}{$\begin{array}{c}\text { Upper permeable } \\
\text { layer } \\
(\text { HGU1) }\end{array}$} & $\begin{array}{l}\text { Zone of low to moderate permeability } \\
\text { (HGU1a) }\end{array}$ & $1.0-27.0$ & $6.1 \times 10^{-2}$ \\
\hline & $\begin{array}{l}\text { Zone of moderate permeability } \\
\text { (HGU1b) }\end{array}$ & $2.0-28.0$ & $2.0 \times 10^{-1}$ \\
\hline & Zone of high permeability (HGU1c) & $0.5-23.0$ & $1.05 \times 10^{0}$ \\
\hline \multirow{2}{*}{$\begin{array}{l}\text { Lower layer of } \\
\text { low permeability } \\
\text { (HGU2) }\end{array}$} & Zone of low permeability (HGU2a) & $1.5-35.0$ & $1.2 \times 10^{-2}$ \\
\hline & $\begin{array}{l}\text { Zone of ultra-low permeability } \\
\text { (HGU2b) }\end{array}$ & $>30$ & $>7.5 \times 10^{-3}$ \\
\hline
\end{tabular}

\section{CONCLUSIONS}

The presented results confirm the applicability and high efficiency of the proposed integrated approach, based on the application of electrical resistivity tomography, exploratory core drilling and slug tests. Layers and relatively small in size zones with different water permeability were successfully outlined in the near-surface section of a region characterized by its complex geological structure. The acquired hydrogeological cross sections were of great importance for the development of an applicable technological solution regarding the construction of a tailings pond near Breznik, Bulgaria.

The proposed approach for data acquiring, analysis and interpretation can be applied very effectively for obtaining quantitative assessments of the hydrogeological conditions in the studied areas. It provides possibilities for a much more precise delineation of the spatial boundaries of geological and hydrogeological units, tectonic faults, fissured and karst zones, water saturated and unsaturated zones, zones characterized by a different degree of water permeability, contaminated areas, etc.

\section{REFERENCES}

[1] Grigorova, M. \& Koprev, I. Geophysical investigations of "Starite kolibi" marble deposit in Central Southern Bulgaria, 5th International Scientific Conference GEOBALCANICA, Bulgaria, 2019, pp 37-42. DOI: 10.18509/GBP.2019.05

[2] Dimovski, S., Stoyanov, N. \& Gyurov, C. Efficiency of electrotomography surveying for geoelectrical mapping of near-surface geological section, BULAQUA Journal, vol. 4, pp 47-55, 2007.

[3] Grigorova, M. \& Koprev, I. Application of electrical resistivity tomography for sand underwater extraction, 4th International Scientific Conference GEOBALCANICA, North Macedonia, 2018, pp 15-20. DOI: 10.18509/GBP.2018.02 
[4] Dimovski, S., Stoyanov, N., Tzankov C. \& Kisyov, A. Application of electrical resistivity tomography for studying fissure-karst water-bearing complexes, 9th Congress of the Balkan Geophysical Society, Turkey, 2017, Paper 44018, 5 p. DOI: 10.3997/ 2214-4609.201702529

[5] Dimovski, S., Stoyanov, N., Tzankov, C. \& Kisyov, A. A geophysical approach for mapping of abandoned mining workings and unconsolidated zones in coal mining areas, Journal of Mining and Geological Sciences, vol. 60, Part I, Geology and Geophysics, pp 99-103, 2017.

[6] Stoyanov, N., Trayanova, M., Dimovski, S. \& Benderev, A. Evaluation of the impact by deep artesian boreholes on fresh ground waters in the terrace of Kamchiya River, Geologica Balcanica, vol. 46 (2), pp 125-133, 2017.

[7] Dimovski, S., Stoyanov, N., Kisyov, A. \& Yankova, M. Detection of zones characterized by different degree of water-saturation and mapping of landslide surfaces by application of electrical tomography, 7th Congress of the Balkan Geophysical Society, Albania, 2013, Paper 18504. 5 p. DOI: $10.3997 / 2214-4609.20131673$

[8] Grigorova, M. \& Koprev, I. 3D model of limestone inclusions in Maritsa Iztok mine based on electrical resistivity tomography, Acta Geobalcanica, vol. 3 (2), pp 51-56, 2017. DOI: 10.18509/AGB.2017.06

[9] Shanov, S., Mitev, A., Benderev, A., Kostov, K. \& Mihailova B. Electrical survey for detailed characterizing of underground karst: Example from Iskar River (Western Bulgaria). 5th Congress of Balkan Geophysical Society, Serbia, 2009.

[10] Kotsev, T., Kolev, S. \& Hristov, V. Modeling of groundwater flow and transport of pollutants caused by a difference in densities (on the example of the valley of Vulche dere creek, downstream of Eleshnitsa tailings pond). Engineering Geology and Hydrogeology, vol. 32, pp 3$12,2018$.

[11] Shanov, S., Vasilev, I., Mitev, A., Hristov, V. \& Mihailova, B. Electrical Tomography for studies of the inner structure of dumps (Open-pit "Ellatzite", Bulgaria), 6th Congress of Balkan Geophysical Society, Hungary, 2011.

[12] Georgieva, G., Kisyov, A., Tzankov, C., Shtirkova, B., Gourev, V. \& Ivanov, Y. Evaluation of geophysical methods for studying snowfields in Pirin Mountain, 10th Congress of the Balkan Geophysical Society, Bulgaria, 2019, Paper BGS2019-ST1.1-N41O2, 5 p. DOI: 10.3997/22144609. 201902662

[13] Griffiths, D. \& Barker, R. Two dimensional resistivity imaging and modeling in areas of complex geology, Journal of Applied Geophysics, vol. 29 (2-3), pp 211-226, 1993. DOI: 10.1016/0926-9851(93)90005-J

[14] Loke, M. Electrical imaging surveys for environmental and engineering studies. A practical guide to 2-D and 3-D surveys. Malaysia, 67 p., 1999.

[15] Loke, M. A practical guide to RES2DINV ver. 3.4; Rapid 2-D resistivity \& IP inversion using the least-squares method. Geotomo Software, Malaysia., 129 p., 2001.

[16] Daniels, F. \& Alberty, R. Physical chemistry, John Wiley \& Sons, New York, USA, 687 p., 1975.

[17] Keller, G. \& Frischknecht, F. Electrical methods in geophysical prospecting. Pergamon Press, Oxford, UK, 519 p., 1966.

[18] Castany, G. Prospection et exploitation des nappes souterraines, Dunod, Paris, France, 718 p, 1968.

[19] Galabov, M. \& Stoyanov, N. Groundwater dynamics, Vanio Nedkov Publ. House, Sofia, Bulgaria, 202 p., 2005. 